\title{
Industrial scale extraction and stripping devices for continuous recovery of gallic acid from Chinese nutgall processing wastewater
}

\author{
Yundong $\mathrm{Wu}^{1,2^{+}}$, Xihe $\mathrm{Xia}^{1}$, Shuyu Dong ${ }^{2}$, Kanggen $\mathrm{Zhou}^{2}$ \\ ${ }^{1}$ School of Life Science and Engineering, Handan University, Handan 056005, Hebei, China \\ ${ }^{2}$ School of Metallurgy and Environment, Central South University, Changsha 410083, Hunan, China
}

\begin{abstract}
In this study, we report the industrial application of an efficient technology for the recovery of gallic acid from Chinese nutgall processing wastewater. The recovery of gallic acid by industrial scale extraction and stripping devices was performed, with tributyl phosphate as the extractant and kerosene as the diluent. The results showed that the theoretical extraction stage was four, while the theoretical stripping stage was two. A closed-cycle system was studied for the continuous countercurrent extraction and stripping, with a five-stage extraction device and a three-stage reflux stripping device. The results showed that the multistage extraction-stripping system could steadily run for a long period, the average gallic acid level in the raffinate was $0.85 \mathrm{~g} \cdot \mathrm{L}^{-1}$, and the gallic acid content recovered in the strip liquor was higher than $120 \mathrm{~g} \cdot \mathrm{L}^{-1}$. The average extraction yield of gallic acid was $94.14 \%$. When the strip liquor was used as raw material for production, the average production yield increased by $8.64 \%$. In addition, after extraction, the $\mathrm{COD}_{\mathrm{Cr}}$ in the wastewater decreased by $38.19 \%$, and the biodegradability of wastewater improved by 1.6 times. This study provided a new impetus for the sustainable development of the Chinese nutgall processing industry.
\end{abstract}

Keywords: Extraction, Gallic acid, Recovery, Stripping, Wastewater

\section{Introduction}

Gallic acid (3,4,5-trihydroxybenzoic acid) is a naturally abundant plant phenolic compound [1]. Gallic acid and its derivatives have been used to prevent and treat a variety of diseases [2, 3], it has beneficial effect such as antitumor [4], trypanocidia [5], also it can protect liver [6], which has caused widespread interest. Gallic acid can be produced from Chinese nutgall, Turkey trough, Tara pod, pomegranate, sumac, or Cotinus coggygria. The methods for producing gallic acid include acid hydrolysis, alkali hydrolysis, biological or enzymatic processes [7]. Generally, manufacturers use the alkali hydrolysis process to produce gallic acid, with Chinese nutgall as the raw material in China [8]. The production of 1 ton gallic acid will generate $6.5 \mathrm{~m}^{3}$ wastewater. The major components and concentrations in the wastewater are: Gallic acid $16.96 \mathrm{~g} \cdot \mathrm{L}^{-1}, \mathrm{COD}_{\mathrm{Cr}} 64,356.5 \mathrm{mg} \cdot \mathrm{L}^{-1}, \mathrm{BOD}_{5} 2,414.0 \mathrm{mg} \cdot \mathrm{L}^{-1}$, salinity $100 \mathrm{~g} \cdot \mathrm{L}^{-1}$, and the $\mathrm{pH}$ value is 0.58 .

The wastewater generated by the alkaline hydrolysis process contains a certain amount of gallic acid, excess $\mathrm{HCl}$ and $\mathrm{NaCl}$ produced during the neutralization reaction [9], which cannot be discharged until meeting the emission guidelines. However, currently the existing industrial applications for the treatment of Chinese nutgall processing wastewater are not effective enough, and the problem of severe environmental pollution is hindering the development of the Chinese nutgall processing industry. Because the environmental regulations have become increasingly stringent, the Chinese nutgall processing industry is facing a significant challenge. Therefore, research and development toward efficient and practical technologies for the treatment of wastewater produced from the gallic acid production process is of significant importance and urgency.

The economic value of gallic acid is high, relinquishing the recovery of gallic acid and treating it directly would lead to a waste of resource. In addition, gallic acid is a component of the chemical oxygen demand $\left(\mathrm{COD}_{\mathrm{Cr}}\right)$ and five day biochemical oxygen demand $\left(\mathrm{BOD}_{5}\right)$; the recovery of gallic acid can decrease the $\mathrm{COD}_{\mathrm{Cr}}$ concen-
This is an Open Access article distributed under the terms of the Creative Commons Attribution Non-Commercial License (http://creativecommons.org/licenses/by-nc/3.0/) which permits unrestricted non-commercial use, distribution, and reproduction in any medium, provided the original work is properly cited.
Received November 23, 2016 Accepted March 13, 2017

${ }^{\dagger}$ Corresponding author

Email: wydccc@gmail.com

Tel: +86-17633398678

Copyright (C) 2017 Korean Society of Environmental Engineers 
tration and improve the biodegradability $\left(\mathrm{BOD}_{5} / \mathrm{COD}_{\mathrm{Cr}}\right.$ ratio) of the wastewater, reducing the difficulty of the biological treatment. Compared with traditional evaporation and crystallization process [10], the recovery efficiency by the extraction process is high, and the operation process is simple, providing an effective means for the recovery and enrichment of gallic acid. In addition, as the extractant can be recycled, the operational cost is much lower. We can not only recover gallic acid from wastewater by the extraction process, but can also reduce the $\mathrm{COD}_{\mathrm{Cr}}$ content as gallic acid is an organic matter, improving the biodegradability of the wastewater, making it conducive for the subsequent biological treatment.

The existing researches have focused on the extraction of trace-scale gallic acid in aqueous solutions [11, 12], which cannot be used for the separation of high gallic acid concentration in wastewater. In our previous work, methyl isobutyl ketone, ethyl acetate, butanol and 30\% tributyl phosphate (TBP)/kerosene were used as extractant to recover gallic acid from actual gallic acid production wastewater [13, 14]. We have found that TBP/kerosene was the best extractant which had the advantages of high extraction yield, good selectivity, rapid separation, and large capacity among others. The reported researches on the recovery of organic acid by extraction were of laboratory scale and the runtime was short [15, 16], it was still unknown how to design industrial production process and what might happen during the long time continuous operation.

The object of this study was to verify the reliability of the continuous recovery of gallic acid by TBP/kerosene extraction system from actual Chinese nutgall processing wastewater. Firstly, we examined the theoretical stages for extraction and stripping, and then designed a complete set of industrial scale extraction and stripping devices based on the theoretical stage study. The devices were operated continuously. In addition, the removal efficiencies of gallic acid and $\mathrm{COD}_{\mathrm{Cr}}$ were studied.

\section{Materials and Methods}

\subsection{Chemicals and Reagents}

Analytical grade gallic acid, $\mathrm{HCl}, \mathrm{NaOH}$, phosphoric acid, and methanol were used in this study. Actual gallic acid processing wastewater was obtained from a biotechnology company in Hunan Province, China.

\subsection{Analysis Methods}

High-performance liquid chromatography (HPLC) (Agilent 1100 LC, Agilent Corp.) with a UV detector was used to analyze the gallic acid concentrations in the aqueous phase $[17,18]$. The separation was performed on a Diamonsil $\mathrm{C}_{18}$ column $(250 \mathrm{~mm}$ $\times 4.0 \mathrm{~mm}, 5 \mu \mathrm{m}$ ), the column temperature was $298 \mathrm{~K}$, and the injection volume of sample was $5.0 \mu \mathrm{L}$. The mobile phase was methanol and $0.05 \%$ phosphoric acid (5:95) which was operated at the flow rate of $1.0 \mathrm{~mL} \cdot \mathrm{min}^{-1}$.

The extraction yield ( $\eta$ ) was calculated by Eq. (1), meanwhile, the gallic acid concentration $\left(C_{O}\right)$ in the organic phase was calculated by Eq. (2), and the distribution ratio (D) was calculated by Eq. (3), the results of which were used as the design parameter in the determination of theoretical stages:

$$
\begin{gathered}
\eta=\frac{C_{W}-C_{R}}{C_{W}} \times 100(\%) \\
C_{O}=\frac{\left(C_{W}-C_{R}\right) V_{A}}{V_{O}} \\
D=\frac{C_{W}-C_{R}}{C_{R}}
\end{gathered}
$$

Where $C_{O}$ represents the gallic acid content in the organic phase; $C_{W}$ and $C_{R}$ represent the gallic acid in the wastewater before pre-treatment and in the raffinate, respectively, in $\mathrm{mg} \cdot \mathrm{L}^{-1}$; $V_{O}$ and $V_{A}$ represent the volumes of organic phase and aqueous phase, respectively, in $\mathrm{L}^{-1}$.

The $\mathrm{COD}_{\mathrm{Cr}}$ levels were determined by rapid digestion and spectrophotometry (UV-1801, Ruili Corp) [19]. The $\mathrm{pH}$ value of the wastewater and raffinate were measured with a $\mathrm{pH}$ meter using a combined electrode (320-S, Mettler Toledo), and the $\mathrm{pH}$ values

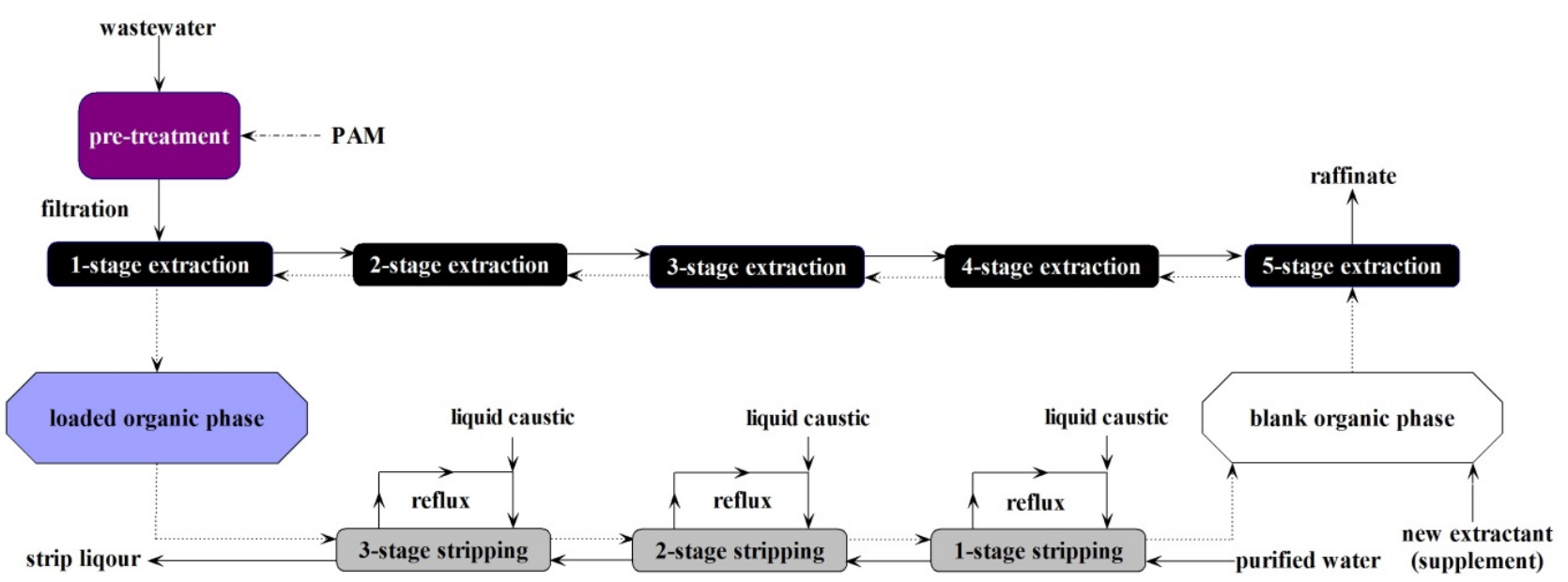

Fig. 1. Schematic diagram of the industrial scale countercurrent extraction and stripping. 
of the three-stage strip liquor were measured using online $\mathrm{pH}$ meters with combined electrodes (OPM 253, Amer \& Innovative Sensors, Inc.).

\subsection{Experimental Setup}

The extraction tank was 4,300 mm long, 4,200 mm wide and $1,400 \mathrm{~mm}$ in height. The stripping tank was $3,250 \mathrm{~mm}$ long, $1,900 \mathrm{~mm}$ wide and $1,400 \mathrm{~mm}$ in height. The extraction and stripping tanks were constructed of polypropylene (PP).

Before pumped into the extraction tank, the wastewater was pre-treated by cationic polyacrylamide (PAM), and was filtered to remove the impurities such as suspended powder activated carbon particles and pectin impurities, among others. The flow rate of the aqueous phase and organic phase in the extraction tank was $1.0 \mathrm{~m}^{3} \cdot \mathrm{h}^{-1}$. To obtain a high gallic acid level in the strip liquor, the flow rate of the loaded organic phase in the stripping tank was controlled at $1.0 \mathrm{~m}^{3} \cdot \mathrm{h}^{-1}$, and the aqueous phase, which was purified water was controlled at $0.1 \mathrm{~m}^{3} \cdot \mathrm{h}^{-1}$. Because the velocity between the loaded organic phase and the aqueous phase was significant different, in each stage of the stripping tank, the aqueous phase was pumped from the clarification chamber to the stirred tank to increase the contact time of the two phases, the reflux flow rate was set at $1.5 \mathrm{~m}^{3} \cdot \mathrm{h}^{-1}$. The caustic soda was pumped into the reflux port to adjust the $\mathrm{pH}$ value (Fig. 1), pH values of the three-stage strip liquor was maintained at approximately 10.

\section{Results and Discussion}

\subsection{The Determination of the Extraction and Stripping Stages}

The theoretical stages of multistage countercurrent extraction and stripping were determined by the McCabe-Thiele diagram [20], using the equilibrium line and operation line. The theoretical stages were studied with actual wastewater as the object, with the phase ratio was 1:1. The process of the multistage countercurrent extraction or stripping was shown in Fig. 2.

The coordinate of point $\mathrm{A}\left(\mathrm{X}_{\mathrm{f}}, \mathrm{Y}_{\mathrm{n}}\right)$ was the gallic acid in the aqueous phase $\mathrm{X}_{\mathrm{f}}$ entering the $\mathrm{n}$-stage and the gallic acid in the organic phase $Y_{n}$ leaving the $n$-stage. The gallic acid content in the aqueous phase $\mathrm{X}_{\mathrm{f}}$ and the gallic acid content in organic phase $Y_{n}$ were in equilibrium in the n-stage. The coordinate of point $\mathrm{B}\left(\mathrm{X}_{\mathrm{n}}, \mathrm{Y}_{\mathrm{n}}\right)$ was the horizontal line passed through point $\mathrm{A}$ and intersected the distribution line. The coordinate of point $C\left(X_{n}\right.$, $\left.\mathrm{Y}_{\mathrm{n}-1}\right)$ was the vertical line across point $\mathrm{B}$ and intersecting the operation line, which was the gallic acid content in the aqueous phase $X_{n}$ entering the n-1-stage and the gallic acid content in the organic phase $Y_{n-1}$ leaving the $n$-1-stage. The coordinate of

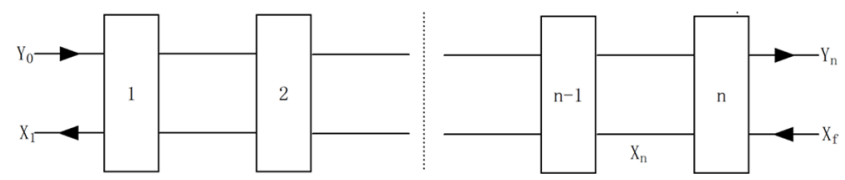

Fig. 2. Schematic diagram of multistage countercurrent extraction or stripping.

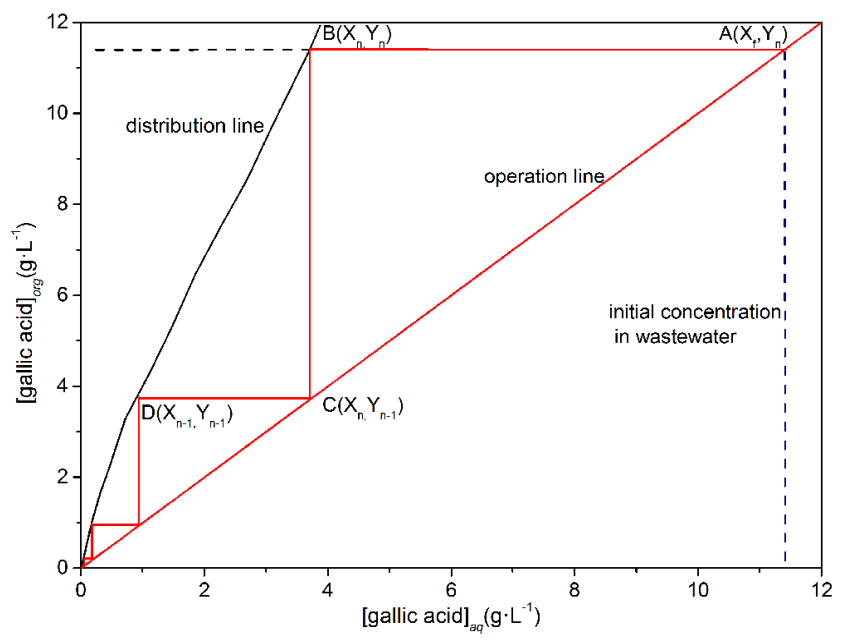

Fig. 3. McCabe-Thiele diagram of multistage countercurrent extraction.

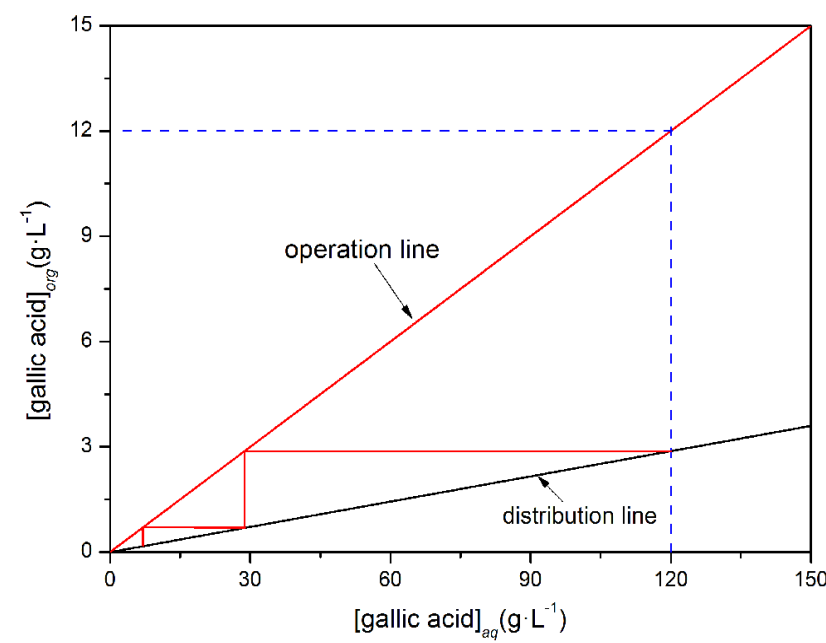

Fig. 4. McCabe-Thiele diagram of multistage countercurrent stripping.

$\mathrm{D}\left(\mathrm{X}_{\mathrm{n}-1}, \mathrm{Y}_{\mathrm{n}-1}\right)$ was the intersection point of the horizontal line from point $\mathrm{C}$ and intersecting the equilibrium line, which repre sented the gallic acid content in the aqueous phase $X_{n-1}$ entering the $n$-1-stage and the gallic acid content in the organic phase $\mathrm{Y}_{\mathrm{n}-1}$ leaving the n-1-stage. This process continued until the gallic acid in the outlet of the aqueous phase was close to $\mathrm{X}_{1}$. The result was the number of steps, which was also the theory stage.

The number of the steps outlined in Fig. 3 was four, which indicated that the theoretical stage for extraction was four. In the same way, we determined that the number of steps for stripping was two (Fig. 4), which indicated that the number of theoretical stages of stripping was two. When we were designing the industrial scale extraction and stripping device, an additional stage for both the extraction and stripping process was added because redundancy design was an effective way to improve the reliability and availability of the extraction - stripping system. If the extraction and stripping yield were not ideal after the theoretical four-stage extraction or two-stage stripping, the additional stage would play the role making the outcome meeting 
the design requirements. Therefore, the actual number of extraction stages was five and stripping stages was three in this study.

\subsection{Continuous Separation of Gallic Acid by Five-stage Extraction}

The gallic acid content in the influent wastewater ranged from $8.95 \mathrm{~g} \cdot \mathrm{L}^{-1}$ to $16.67 \mathrm{~g} \cdot \mathrm{L}^{-1}$ (Fig. 5) during the continuous operation of the industrial scale extraction, but the change of the influent content had no significant effect on the extraction efficiency. The gallic acid levels in the raffinate increased from $0.37 \mathrm{~g} \cdot \mathrm{L}^{-1}$ to $0.80 \mathrm{~g} \cdot \mathrm{L}^{-1}$ during the initial $17 \mathrm{~d}$, and subsequently did not change after $17 \mathrm{~d}$. During $17 \mathrm{~d}$ to $212 \mathrm{~d}$, the average gallic acid concentration in the raffinate was $0.85 \mathrm{~g} \cdot \mathrm{L}^{-1}$, and the average extraction yield was $94.14 \%$, no down trend was shown, which indicated that the separation efficiency was good, the ideal recovery efficiency could be obtained and the five-stage countercurrent extraction was stable for long-term and continuous operation.

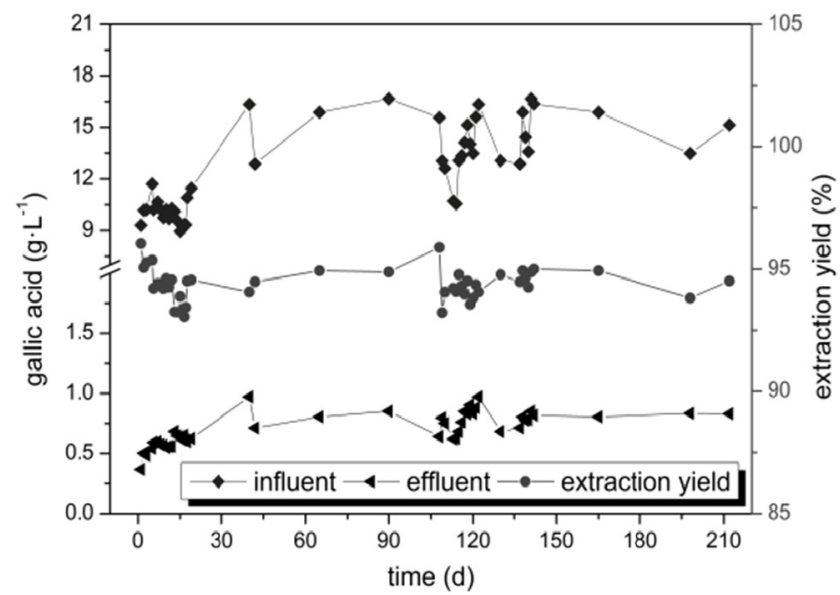

Fig. 5. Industrial scale continuous extraction of gallic acid from actual wastewater with the five-stage extraction tank.

\subsection{Continuous Recovery of Gallic Acid by Three-stage Reflux Stripping}

The gallic acid concentration in the strip liquor of the three-stage stripping was approximately $120 \mathrm{~g} \cdot \mathrm{L}^{-1}$ (Fig. 6), as gallic acid content in the wastewater produced by the hydrolysis process was $16.96 \mathrm{~g} \cdot \mathrm{L}^{-1}$ as shown in Table 1 , it was 7.5 times higher than the gallic acid content in the wastewater. The gallic acid level in the aqueous phase of the two-stage stripping ranged from 4.94 to $34.76 \mathrm{~g} \cdot \mathrm{L}^{-1}$ during operation, which was caused by occasionally incomplete stripping in the third stage stripping tank. The gallic acid concentration in the aqueous phase of the first stage stripping tank was less than $2 \mathrm{~g} \cdot \mathrm{L}^{-1}$; thus, we could deduce that the gallic acid level in the organic phase was less than $0.6 \mathrm{~g} \cdot \mathrm{L}^{-1}$ based on the stripping isotherms [14]. The production yield of gallic acid by traditional alkali hydrolysis was about 80\% [21]. During 9-Oct-2014 to 27-Dec-2014, when the strip liquor was used as raw material, the average production yield was $88.64 \%(\mathrm{n}=17, \mathrm{SD}=0.42)$, therefore, the product yield was $8.64 \%$ higher.

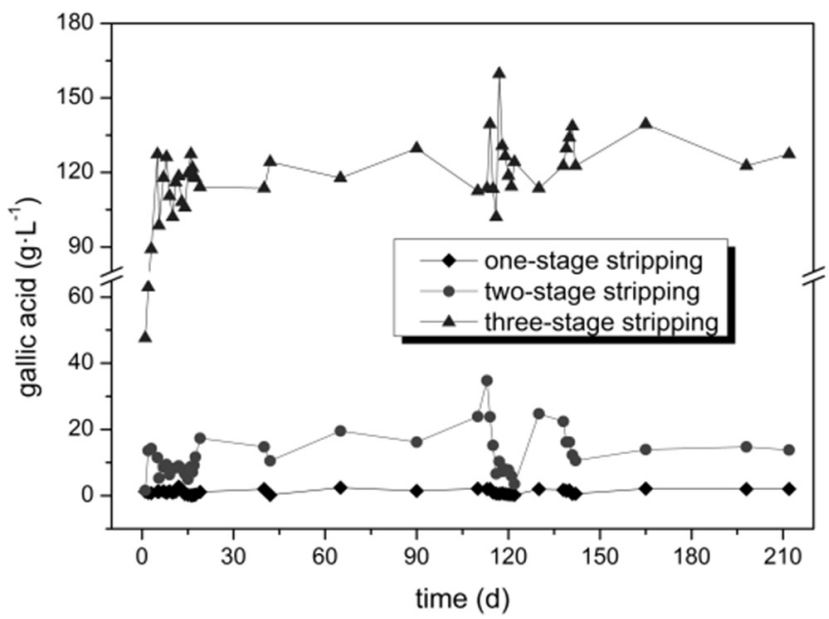

Fig. 6. Industrial scale continuous recovery of gallic acid with the three-stage reflux stripping tank.

The extraction and stripping tanks were connected in series and operated continuously. After stripping, the loaded organic phase changed into blank organic phase and re-entered into the extraction tank, which was a closed loop system. During operation, we found that the low-level gallic acid concentration remaining in the organic phase had no obvious effect on the extraction process, which indicated that the recovery of gallic acid by the three-stage reflux stripping was feasible.

\subsection{Separation Efficiency of Gallic Acid among Different Extraction Stages}

The gallic acid content in the influent, pre-treatment and effluent of the different stages of extraction (Fig. 7) was analyzed on 20 d, $70 \mathrm{~d}, 105 \mathrm{~d}, 125 \mathrm{~d}$ and $144 \mathrm{~d}$, respectively. From the results we could see that after the five-stage extraction, the total extraction yield was $94.11 \%$, and the gallic acid concentration remaining in the raffinate was $0.83 \mathrm{~g} \cdot \mathrm{L}^{-1}$, which indicated that the ideal extraction effect could be obtained by the five-stage countercurrent extraction.

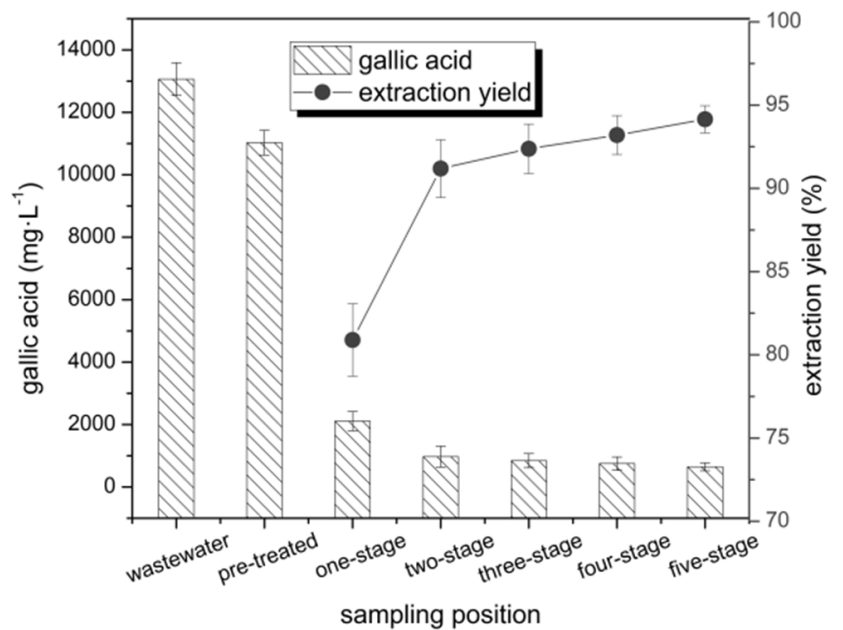

Fig. 7. Change of gallic acid levels among the different extraction stages. 


\section{5. $\mathrm{COD}_{\mathrm{cr}}$ Removal Efficiency among Different Extraction Stages}

The days when $\mathrm{COD}_{\mathrm{Cr}}$ samples taken were the same as the time of gallic acid samples taken: 20 d, 70 d, 105 d, 125 d and 144 d. After the pre-treatment and five-stage extraction (Fig. 8), the $\mathrm{COD}_{\mathrm{Cr}}$ content in wastewater decreased by $38.20 \%$ on average. The small portion of $\mathrm{COD}_{\mathrm{Cr}}$ removed by the pre-treatment was because of the removal of suspended solids, gum, and organic matters adsorbed on powdered activated carbon (loaded with gallic acid) by the polyacrylamide (PAM)-based flocculent. The primary reason for the reduction of $\mathrm{COD}_{\mathrm{Cr}}$ by the extraction process was that the organic matter gallic acid was separated from wastewater and transferred into the organic phase. The $\mathrm{COD}_{\mathrm{Cr}}$ concentration decreased with the increasing stages of extraction, and the effluent $\mathrm{COD}_{\mathrm{Cr}}$ in the raffinate reduced to approximately $35,000 \mathrm{mg} \cdot \mathrm{L}^{-1}$. After extraction, the $\mathrm{BOD}_{5}$ level in the wastewater decreased to $2,106.4 \mathrm{mg} \cdot \mathrm{L}^{-1}$, and the $\mathrm{BOD}_{5} / \mathrm{COD}_{\mathrm{Cr}}$ ratio was 1.61 times than before extraction, also because gallic acid which could inhibit the growth and metabolism of microorganisms [22, 23] was separated, the biodegradability of the wastewater was significantly improved.

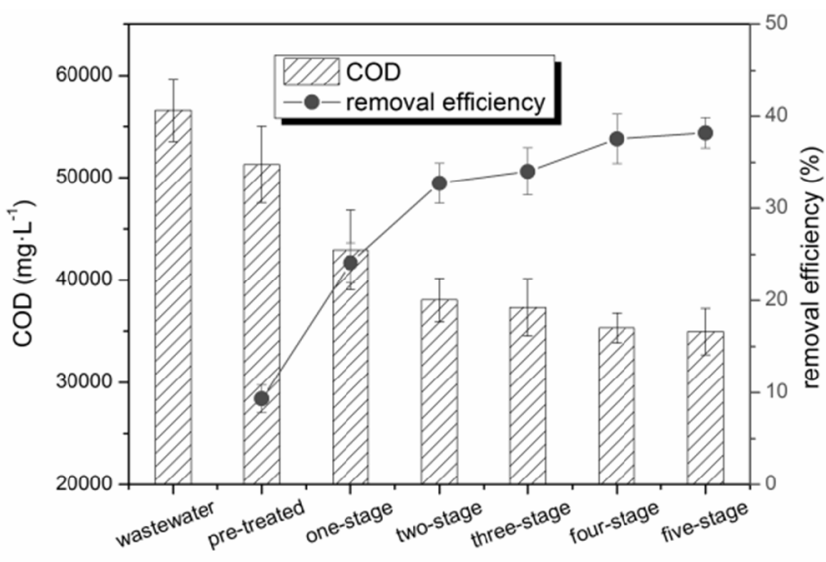

sampling position

Fig. 8. Change of $\mathrm{COD}_{\mathrm{Cr}}$ concentrations among different extraction stages.

\section{Conclusions}

The continuous recovery of gallic acid by TBP/kerosene extraction system from actual Chinese nutgall processing wastewater was a reliable method. The use of $30 \% \mathrm{TBP} /$ kerosene as an extractant resulted in excellent recovery of gallic acid from Chinese nutgall processing wastewater. The extraction efficiency was high, the operation conditions were mild, and the separation of the product was simple. The process route was a closed loop system, which could run continuously. In addition to the recovery of the valuable gallic acid component obtaining economic value from the wastewater by the extraction process, the biodegradability of the wastewater was also significantly improved, which provided favorable conditions for the smooth performance of the sub-sequent biological treatment.

\section{Acknowledgments}

This study was supported by the Strategic Project of Science and Technology of Hunan Province, China [Grant No 2014GK1059]. The authors would like to thank the members of the Research Group for Extraction and Separation Chemistry who co-operated with the present study.

\section{References}

1. Lopez-Velez M, Martinez-Martinez F, Valle-Ribes CD. The study of phenolic compounds as natural antioxidants in wine. Crit. Rev. Food. Sci. 2003;43:233-244.

2. Chang L, Zhang Z, Huang J, Xu H, Zhong C. Review on preparation and application of gallic acid. Biomass. Chem. Eng. 2010;44:48-52.

3. Li X, Cui L, Zhu D. Progress of study on the biological effect of gallic acid. China. Pharm. 2004;7:767-769.

4. Faried A, Kurnia D, Faried LS, et al. Anticancer effects of gallic acid isolated from Indonesian herbal medicine, Phaleria macrocarpa (Scheff.) Boerl, on human cancer cell lines. Int. J. Oncol. 2007;30:605-613.

5. Koide T, Nose M, Inoue M, Ogihara Y, Yabu Y, Ohta N. Trypanocidal effects of gallic acid and related compounds. Planta Med. 1998;64:27-30.

6. Ohno T, Inoue M, Ogihara Y. Cytotoxic activity of gallic acid against liver metastasis of mastocytoma cells P-815. Anticancer Res. 2000;21:3875-3880.

7. Zhang Y, Li J, Liu L, Yu Z, Ma Q, Li M. Research process in gallic acid from Galla Chinensis. Sci. Tech. Food. Ind. 2013;34:386-390.

8. Zheng S, Huang J, Wu Q, Sha S. Studies on separation and antibacterial activity of the effective components of Chinese herbal compounds gallnut for fishery antimicrobial agent. Acta. Hydrobiol. Sin. 2010;34:57-64.

9. Qin Q. Pollution control on industrialization of gallotannin. Chem. Ind. Forest Prod. 2008;28:73-76.

10. Qin Q. Techniques for treatment and recovery of effluents, residues and wasted carbon from gallic acid production. Chem. Ind. Forest Prod. 2000;34:15-20.

11. Cláudio AFM, Ferreira AM, Freire CS, Silvestre AJ, Freire MG, Coutinho JA. Optimization of the gallic acid extraction using ionic-liquid-based aqueous two-phase systems. Sep. Purif. Technol. 2012;97:142-149.

12. Soong YY, Barlow PJ. Quantification of gallic acid and ellagic acid from longan (Dimocarpus longan Lour.) seed and mango (Mangifera indica L.) kernel and their effects on antioxidant activity. Food Chem. 2006;97:524-530.

13. Yu W, Zhou K, Wu Y, Du H. Extraction technology for recovery of gallic acid from gallic mother liquor. CIESC J. 2013;64: 1660-1664.

14. Wu Y, Zhou K, Dong S, Yu W, Zhang H. Recovery of gallic acid from gallic acid processing wastewater. Environ. Technol. 2015;36:661-666.

15. Cerqueira MB, Caldas SS, Primel EG. New sorbent in the dispersive solid phase extraction step of quick, easy, cheap, 
effective, rugged, and safe for the extraction of organic contaminants in drinking water treatment sludge. J. Chromatogr. A. 2014;1336:10-22.

16. Gürbüz EI, Alonso DM, Bond JQ, Dumesic JA. Reactive extraction of levulinate esters and conversion to $\gamma$-valerolactone for production of liquid fuels. ChemSusChem 2011;4:357-361.

17. Queimada AJ, Mota FL, Pinho SP, Macedo EA. Solubilities of biologically active phenolic compounds: Measurements and modeling. J. Phys. Chem. B. 2009;113:3469-3476.

18. Weidenhamer J, Li M, Allman J, Bergosh R, Posner M. Evidence does not support a role for gallic acid in phragmites australis invasion success. J. Chem. Ecol. 2013;39:323-332.

19. Pliego G, Zazo JA, Casas JA, Rodriguez JJ. Case study of the application of Fenton process to highly polluted wastewater from power plant. J. Hazard. Mater. 2013;252-253:180-185.

20. McCabe WL, Thiele E. Graphical design of fractionating columns. Ind. Eng. Chem. Res. 1925;17:605-611.

21. Chen J. Situation and prospect of chemical utilization of gallotannins in China. Chem. Ind. Forest Prod. 2000;20:71-82.

22. Uhde A, Youn J, Maeda T, et al. Glucosamine as carbon source for amino acid-producing Corynebacterium glutamicum. Appl. Microbiol. Biotechnol. 2013;97:1679-1687.

23. Baron JA, Laws KM, Chen JS, Culotta VC. Superoxide triggers an acid burst in Saccharomyces cerevisiae to condition the environment of glucose-starved cells. J. Biol. Chem. 2013;288: 4557-4566. 